\title{
Fish Products in the Ancient Mediterranean: Smell, Taste and Texture of Flesh in a Conference Hall
}

\author{
Dimitra Mylona ${ }^{1} \cdot$ Sally Grainger ${ }^{2}$ \\ Published online: 15 November 2018 \\ (c) Springer Science+Business Media, LLC, part of Springer Nature 2018
}

In studying fish products in the ancient Mediterranean we explore textual and archaeological sources to understand the fish preservation processes, to estimate the volume of production, to infer the nature and richness of the raw materials, and, ultimately, to understand how this industry was embedded in the economies of the past. The papers and posters in the Bountiful Sea Conference have demonstrated the richness of these approaches and they have elaborated on the potential of future research.

Departing from the sphere of production, fishing grounds, salting vats and foul smelling cetariae, the salted fish, the fish sauces and pastes became food, a desired commodity. Processed fish products in antiquity were known by a large variety of names: garum, liquamen, muria, allec; names that derived from their shape, the method of processing, the species and the body parts that were processed, their origin, their colour and their texture, to name only some possibilities (Figs. 1,2). Names are descriptive and informative. They reflect the way people order their world. The abundance of names for salted fish and sauces suggest an intense social interest in them. Most importantly these names are closely linked to the sphere of consumption. Some presentations in the Bountiful Sea Conference elaborated on such aspects: processed fish on the table, in cuisine and in medicine.

Eating is not a simple process and it is not only about sustenance; by eating we incorporate the world and we define ourselves! When eating, taste, smell, texture and also the memories these evoke are crucial. The stories around the food we eat are also very important! These immaterial aspects of the past are the most elusive to modern researchers (e.g. Lupton 1996; Tarlow 2000). The Bountiful Sea Conference attempted to explore them by offering opportunities of an experiential approach to the issue in parallel to the academic program. A number of culinary events and experiences were organized along with presentations of modern-day fish products by the producers themselves.

The celebratory event of the conference was the "Roman Feast" that took place in the Ashmolean Museum. Food historian Sally Grainger in collaboration with chef Mike Dewing, set the table with replicas of Roman Samian ware platters, bowls and glass bottles, with Mediterranean fruits and greens (Fig. 3). This event gave the participants the opportunity to form a multisensory personal view of what seafood and processed fish look and taste like, of what are

Dimitra Mylona

dmylona@hotmail.com

1 INSTAP Study Center for East Crete, Ierapetra, Greece

2 Grayshott Hindhead, Surrey, UK 
Fig. 1 Triros, salted and sundried lean Atlantic mackerel (Scomber scombrus), North Aegean, Greece (D. Mylona)
Fig. 2 Lakerda, salted Atlantic bonito (Sarda sarda), Mytilene Island, North Aegean, Greece (D. Mylona)
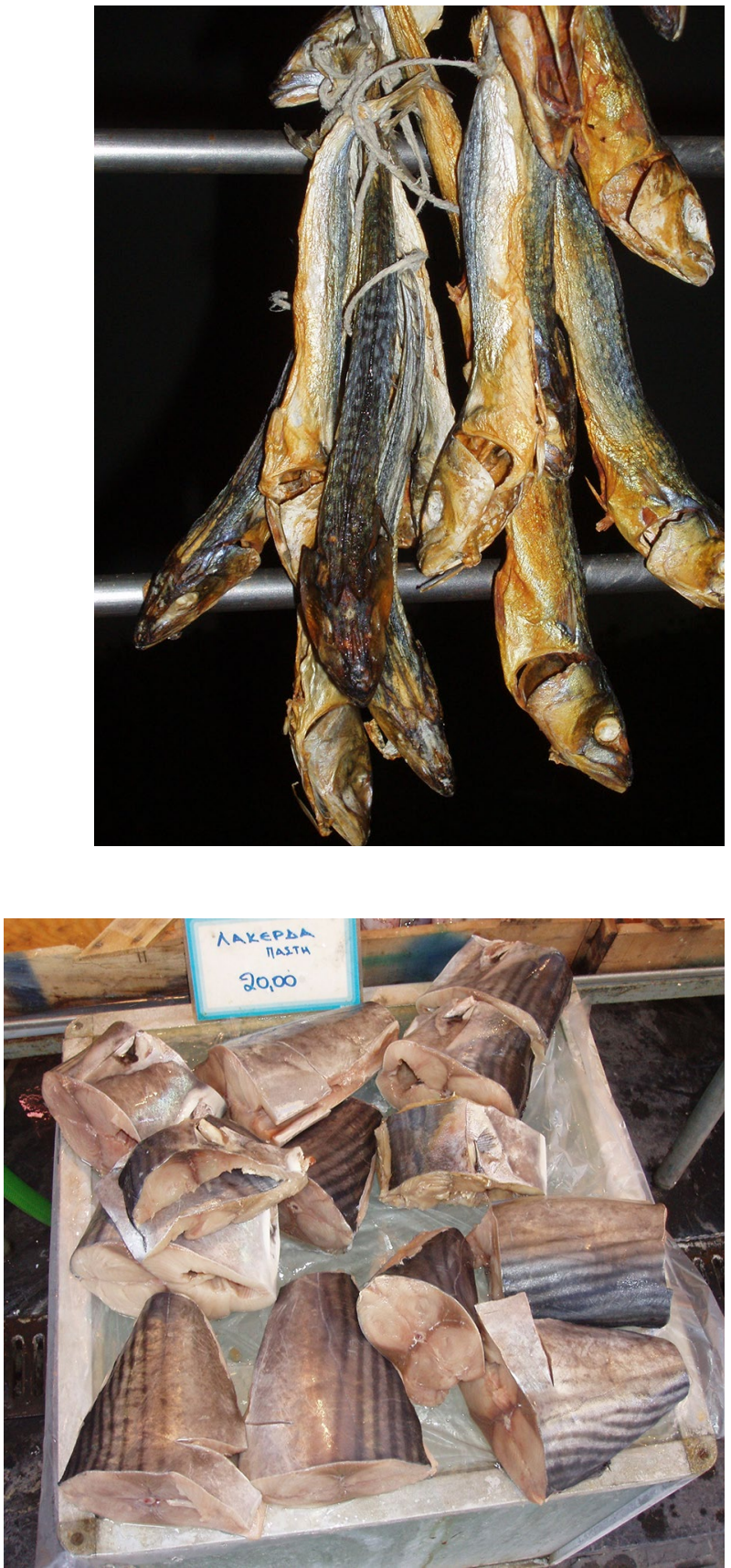

the smells and textures one can praise or abhor. Garum and salt fish were ingredients to many of the dishes (Fig. 4). The participants tasted Cicero's everyday staple, the patina tyrotaricham: (Cicero, Epis. ad Fam 9.16.7.4, 9.16.9.2), salt fish frittata made with tuna and mackerel freshly salted for the occasion; steamed oysters with salsa verde and raw oysters served, as Martial advices (Ep. 13.82), with that infamous black garum. This unique combination was 
Fig. 3 The "Roman Feast" table settings, Ashmolean Museum, Oxford, UK (S. Hay)
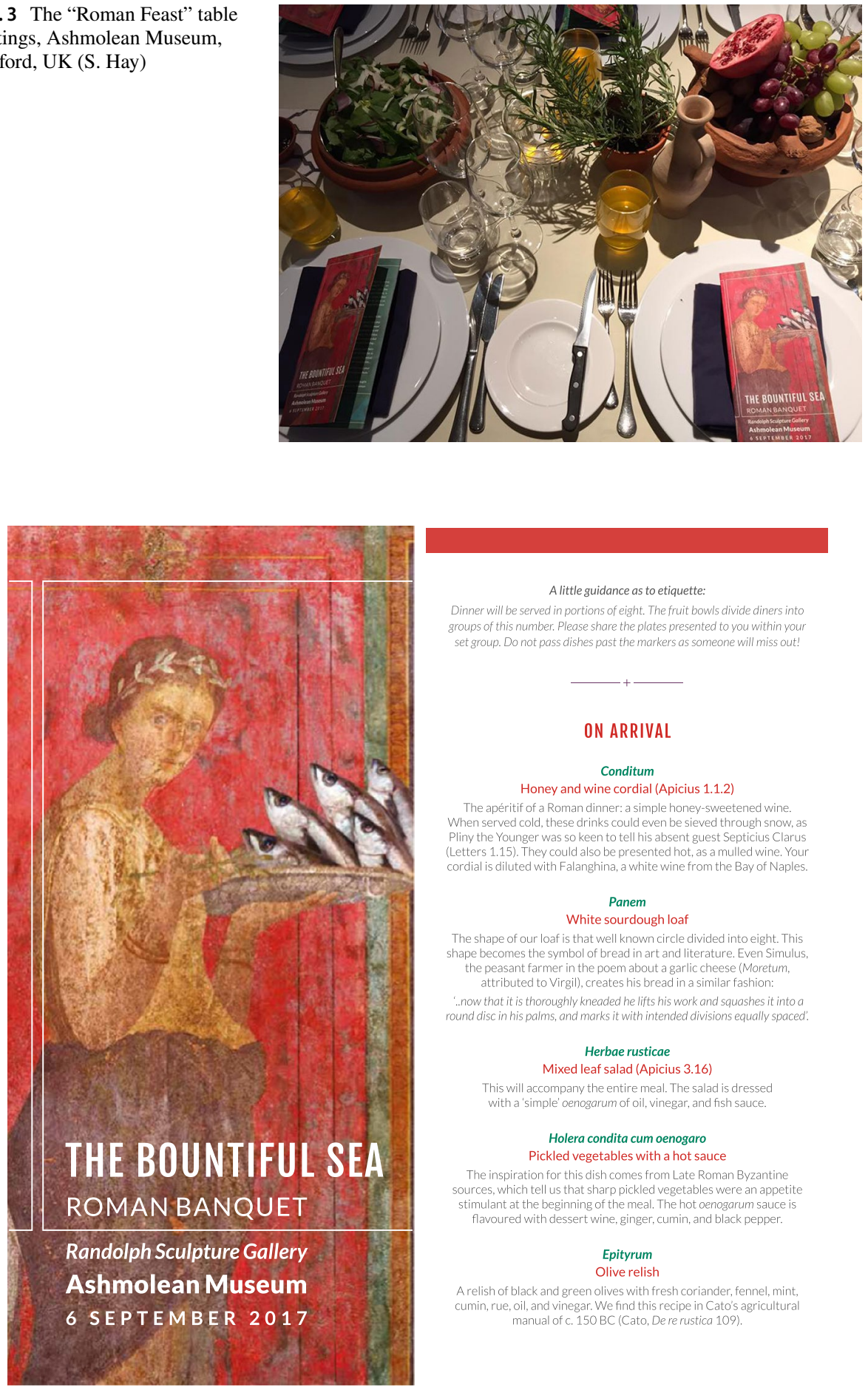

A little guidance as to etiquette:

Dinner will be served in portions of eight. The fruit bowls divide diners into groups of this number. Please share the plates presented to you within your set group. Do not pass dishes past the markers as someone will miss out!

\section{ON ARRIVAL}

Conditum

Honey and wine cordial (Apicius 1.1.2)

The apéritif of a Roman dinner: a simple honey-sweetened wine. When served cold, these drinks could even be sieved through snow, as Pliny the Younger was so keen to tell his absent guest Septicius Clarus (Letters 1.15) They could also be presented hot, as a mulled wine Your cordial is diluted with Falanghina, a white wine from the Bay of Naples.

Panem

White sourdough loaf

The shape of our loaf is that well known circle divided into eight. This shape becomes the symbol of bread in art and literature. Even Simulus, the peasant farmer in the poem about a garlic cheese (Moretum, attributed to Virgil), creates his bread in a similar fashion:

' now that it is thoroughly kneaded he lifts his work and squashes it into a round disc in his palms, and marks it with intended divisions equally spaced'

\section{Herbae rusticae}

Mixed leaf salad (Apicius 3.16)

This will accompany the entire meal. The salad is dressed with a simple oenogarum of oil, vinegar, and fish sauce.

Holera condita cum oenogaro Pickled vegetables with a hot sauce

The inspiration for this dish comes from Late Roman Byzantine sources, which tell us that sharp pickled vegetables were an appetite stimulant at the beginning of the meal. The hot oenogarum sauce is flavoured with dessert wine, ginger, cumin, and black pepper.

\section{Epityrum}

Olive relish

A relish of black and green olives with fresh coriander, fennel, mint, cumin, rue, oil, and vinegar. We find this recipe in Cato's agricultural manual of c. 150 BC (Cato, De re rustica 109).

Fig. 4 The "Roman Feast" menu with a variety of dishes and ingredients (A. Trentacoste, S. Grainger) 


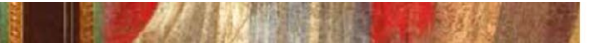

tASTING PLATES

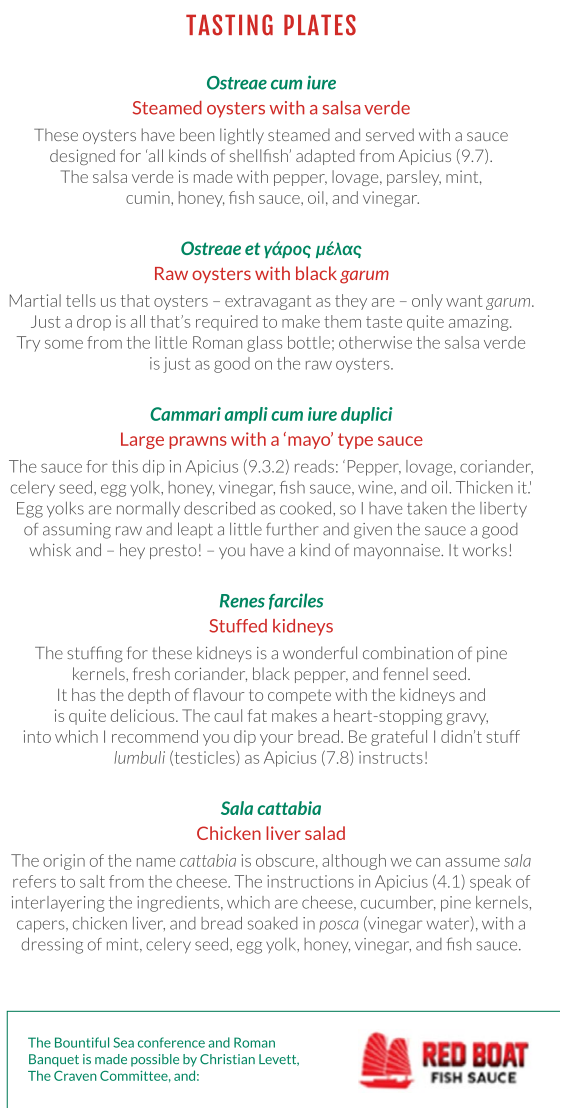

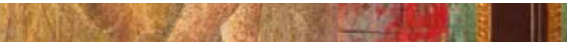

Fig. 4 (continued)

appreciated by many. Examples of finger foods served with a dipping sauce called oenogarum were also offered. Oenogarum is a compound dressing resembling a vinaigrette, though made with delicate use of spice and herb as well as fish sauce with oil and vinegar or wine. These new sensations of exotic combinations of strange ingredients were set against the milder tastes of plain baked fish or meat such as stuffed kidneys and a sweet and sour cabbage dish so completely familiar and modern.

The sensory approach to processed fish continued with a bounty of flavors and images of the "bring and share" buffet at the end of the first full day of academic presentations. Participants from various circum-Mediterranean countries contributed with processed fish from their homelands. Gray mullet bottarga from Greece and Spain, pickled Atlantic bonito from Murcia, salted tuna from Spain and salted sardines from Greece, tinned sardines from Portugal and gefilte fish from Israel, incorporate long-lived traditions in fish preservation around the Mediterranean. Some are still produced in the same way that is described in ancient written sources and some offer new solutions to the old need for processing and preservation (Fig. 5). Garum that was produced experimentally, following the ancient recipes, added to the range of 
Fig. 5 Salted chub mackerel (Scomber japonicus) served as an appetizer with olive oil, Porto Lagos, North Aegean, Greece (D. Mylona)

Fig. 6 From the left: Japanese Ishiri-squid viscera sauce close to a true bloody garum; "Red Boat" fish sauce; an oenogarum of oil, wine and "Red Boat" fish sauce; American garum-made with mackerel fermented for 6 months; tuna muria - salted fresh tuna brine. Various replica Roman vessels associated with fish sauce service (S. Grainger)
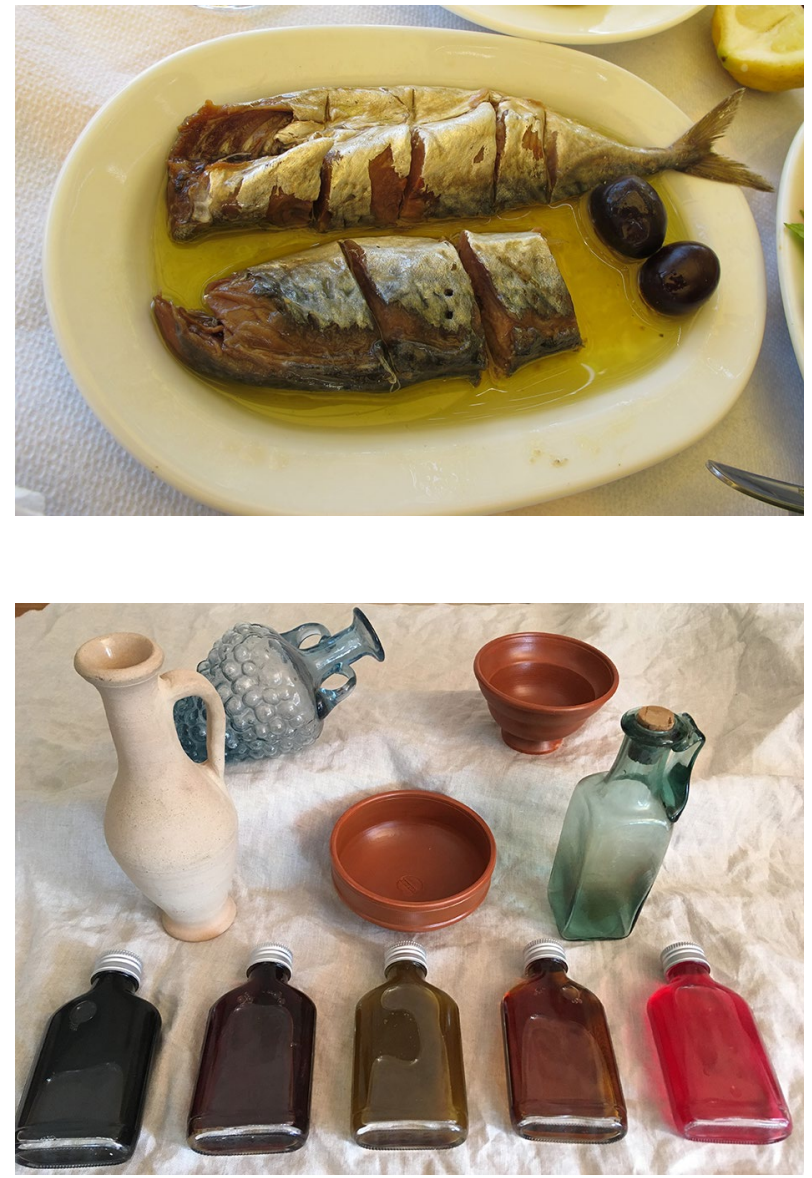

processed fish products available for tasting (Fig. 6). Participants had the opportunity to comprehend the reality of eating the various types of fish products, the differences in taste, aroma, texture and aftertaste each one generated. Tasting these at the end of a day full of presentations and discussions of fish products gave participants a powerful, and often surprising and enjoyable, experience of the reality of consuming ancient preserved fish.

The hands-on approach to fish products was complemented by demonstrations by modern entrepreneurs (Fig. 7). The producer of the Vietnamese fish sauce "Red Boat" who rejected the taste of mass commercially produced fish sauce in his country turned to the traditional recipes of his forbearers, achieving a high-quality product. By contrast, "Green Pastures", introduced the participants to the idea of a fermented cod liver oil which, though predominantly medieval in concept, harks back to the original ancient fish sauces in their use of natural fermentation to achieve exceptional health benefits. 

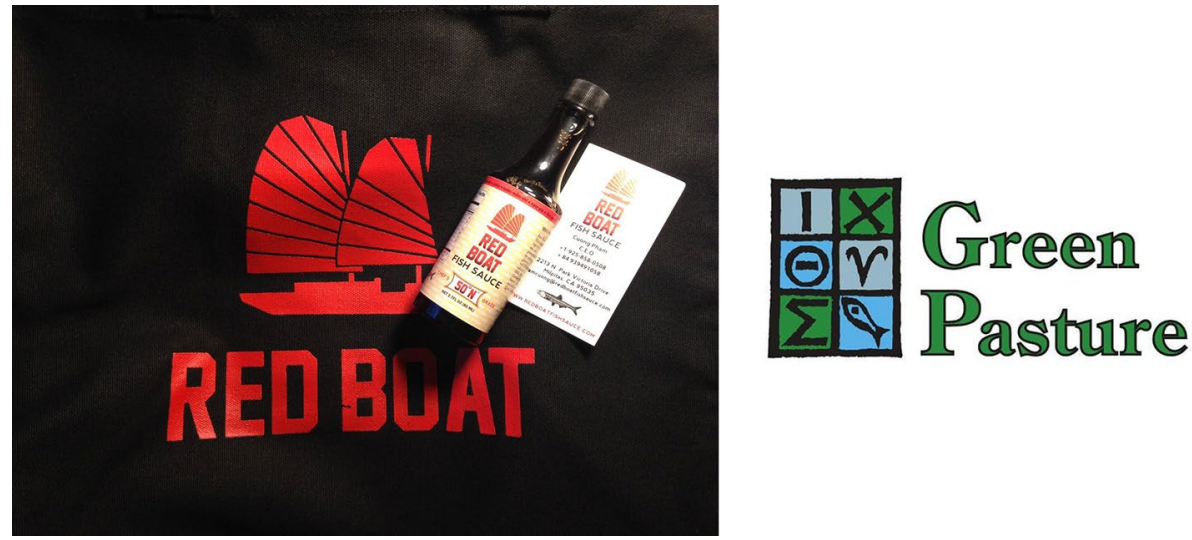

Fig. 7 "Red Boat" and "Green Pastures" produce fish products drawing knowledge and inspiration for ancient traditions on fermented fish products
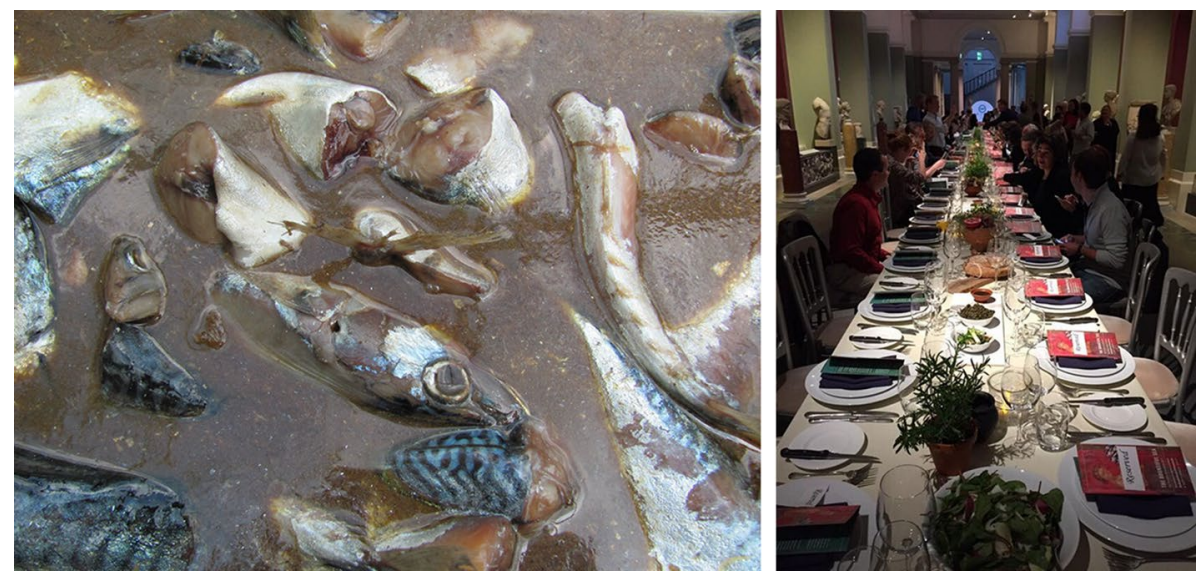

Fig. 8 Left: liquamen fish sauce in the process of dissolving through enzyme hydrolysis; the intense smell of the process is considered highly unappealing (made with Atlantic mackerel, Scomber scombrus, and salt). Right: The Roman feast table setting in the Ashmolean Museum, Oxford; in such a setting fish sauces became highly desirable, possessing the power to transform the taste of food (S. Grainger and S. Hay)

For all participants of the Bountiful Sea Conference, any discussion on salted fish and fish sauces now evokes memories of images, smells, textures tastes and aftertastes (Fig. 8). We hope that this will enrich our understanding of processed fish products.

\section{References}

Lupton D (1996) Food, the body and the self. Sage Publications, London Tarlow S (2000) Emotion in archaeology. Curr Anthropol 41(5):713-746 